\title{
Australian podiatrists scheduled medicine prescribing practices and barriers and facilitators to endorsement: a cross-sectional survey
}

kristin graham ( $\sim$ kristin.graham@unisa.edu.au )

University of South Australia https://orcid.org/0000-0002-1864-1856

Lisa Matricciani

University of South Australia

Helen Banwell

University of South Australia

Saravana Kumar

University of South Australia

Ryan Causby

University of South Australia

Saraid Martin

University of South Australia

Lisa Nissen

Queensland University of Technology - QUT: Queensland University of Technology

\section{Research Article}

Keywords: Podiatry, Prescribing, Endorsement for Scheduled Medicine

Posted Date: November 19th, 2021

DOI: https://doi.org/10.21203/rs.3.rs-1069172/v1

License: (c) (i) This work is licensed under a Creative Commons Attribution 4.0 International License.

Read Full License

Version of Record: A version of this preprint was published at Journal of Foot and Ankle Research on February 8th, 2022. See the published version at https://doi.org/10.1186/s13047-022-00515-w. 
AUSTRALIAN PODIATRISTS PRESCRIBING

Australian podiatrists scheduled medicine prescribing practices and barriers and facilitators to endorsement: a cross-sectional survey

\section{Authors:}

Dr Kristin Graham ${ }^{1}$, Lisa Matricciani ${ }^{1,2}$, Dr Helen Banwell ${ }^{1}$, A/Prof Dr Saravana Kumar ${ }^{1}$, Dr Ryan Causby ${ }^{1}$, Mrs Saraid Martin ${ }^{1}$, Prof Lisa Nissen ${ }^{3}$

\section{Affiliations:}

1. Allied Health \& Human Performance

The University of South Australia

North Terrace

Adelaide SA 5000

Australia

Telephone: +61 883021684

Facsimile: +61 883022853

2. Clinical \& Health Sciences

The University of South Australia

North Terrace

Adelaide SA 5000

Australia

3. Faculty of Health

School of Clinical Sciences

Queensland University of Technology

Brisbane QL 4000

Australia

Correspondence to Kristin Graham: kristin.graham@unisa.edu.au,

Number of tables $\&$ figures: 2 tables and 3 figures 


\title{
AUSTRALIAN PODIATRISTS PRESCRIBING
}

\begin{abstract}
Background

Non-medical prescribing is one healthcare reform strategy that has the potential to create savings in the health system as well as offer equitable and timely access to scheduled medicines. Currently there is a lack of information about prescribing practices of Australian podiatrists, making it difficult to assess if endorsement for scheduled medicines (endorsement) for podiatrists provides health system efficiencies or improved patient access and outcomes. Further, the uptake for endorsement remains low among Australian podiatrists. The aim of this research was to investigate the prescribing practices among Australian podiatrists as well as to explore barriers and facilitators that influence participation in endorsement.
\end{abstract}

\section{Methods}

Participants in this quantitative, cross-sectional study were registered and practicing Australian podiatrists and podiatric surgeons who were recruited through a combination of professional networks, social media, and personal contacts. Respondents were invited to complete a customised self-reported online survey. The survey was developed using previously published research, research team's expertise and piloted with podiatrists. The survey contained three sections: demographic data including clinical experience, questions pertaining to prescribing practices, and barriers and facilitators of the endorsement pathway.

\section{Results}

Respondents $(\mathrm{n}=225)$ were predominantly female, aged $25-45$, working in the private sector. Approximately one quarter were endorsed (15\%) or in training to become endorsed (11\%). Of the 168 non-endorsed respondents, $66 \%$ reported that they would like to undertake training to become an endorsed prescriber.

The medications most frequently prescribed include local anaesthetics, antimycotics, antibacterial agents, and analgesia. The most common indications reported for prescribing these medications include nail surgery (71\%), foot infections and ulcerations (88\%), post-operative pain (67\%), and mycosis (95\%). The most prescribed Schedule 2 medications were ibuprofen, paracetamol, and topical terbinafine. The most prescribed Schedule 4 medicines among endorsed 


\section{AUSTRALIAN PODIATRISTS PRESCRIBING}

podiatrists included lignocaine (84\%), Cephalexin (68\%), Flucloxacillin (68\%), and Amoxicillin with Clavulanic acid (61\%).

\section{Conclusion}

While podiatrists predominantly prescribe to assist pain, inflammatory, or infectious conditions, lack of public funding and pathology testing access limit podiatrists' ability to maximise prescribing opportunities. Many barriers exist in the current endorsement for podiatrists, particularly related to training processes, including mentor access and supervised practice opportunities, requiring targeted enabling strategies.

Key words

Podiatry, Prescribing, Endorsement for Scheduled Medicine 


\section{AUSTRALIAN PODIATRISTS PRESCRIBING}

\section{Background}

In Australia there is a documented shortage of medical practitioners in many areas which impacts on the prescription of scheduled medicines amongst other concerns (1). This will only increase in the context of an aging population, rising chronic disease, and rural and remote workforce shortages (2-4). Non-medical prescribing is one healthcare reform strategy that has the potential to offer equitable and timely access to scheduled medicines $(2,5)$. The increasing use of nonmedical prescribing has been shown to be cost effective and to improve patient satisfaction while not compromising care or safety $(6,7,8)$. Such strategies aim to build a flexible, responsive, and sustainable Australian healthcare workforce that fully utilises workforce resources and competencies $(3,4,9)$.

The Health Practitioner Regulation National Law, enacted by all Australian States and Territories, enables the national health practitioner boards to endorse the registration of suitably qualified health practitioners to prescribe scheduled medicines (10). Healthcare professionals able to gain endorsement to prescribe scheduled medicines (endorsement) in Australia include: pharmacists, nurses, midwives, dentists, optometrists, and podiatrists (11). Although the Podiatry Board of Australia has been able to endorse podiatrists and podiatric surgeons to prescribe scheduled medicines since 2010, less than $3 \%$ of Australian registered podiatrists have gained endorsement (12).

All Australian podiatrists, regardless of endorsement status, can prescribe a range of Schedule 2 (pharmacy medicine), Schedule 3 (pharmacist only medicines) medicines, and administer local anaesthetics (a Schedule 4 (S4) prescription only medicine). Endorsed podiatrists can prescribe an additional list of S4 (prescription only medicines) and S8 (controlled drug) medicines (10). In addition to national regulation, each State and Territory has drug and poisons legislation (11) which prescribers must comply with. Therefore, the schedule medicines podiatrist can prescribe varies across jurisdictions (11).

Podiatrists frequently assess, diagnosis, and intervene in painful musculoskeletal injuries, inflammatory conditions, skin and soft-tissue infections, high risk and diabetic foot disease, and fungal infections (13). Therefore, endorsed podiatrists are well positioned to reduce inconveniences and prevent duplicate visits to general practitioners. Timely prescription of scheduled medicines, such as antibiotic therapy for infected foot ulcers, may prevent 


\section{AUSTRALIAN PODIATRISTS PRESCRIBING}

deterioration and subsequent hospitalisation and/or limb amputation. Similarly, the ability to prescribe appropriate analgesia and anti-inflammatory medications for acute musculoskeletal injuries and inflammatory condition (such as gout) may limit complications and emergency department presentations. However, as podiatrists are not covered under the Australian Pharmaceutical Benefits Scheme (PBS)(14), which provides medicines at a Governmentsubsidised price and collates prescription histories, there is a lack of quantitative information about prescribing practices of podiatrists, making it difficult to assess if endorsement for podiatrists leads to health system efficiencies or improved patient access and outcomes.

Little is known about why the uptake for endorsement for scheduled medicines remains low among Australian podiatrists. Graham and colleagues (15), in a qualitative thematic analysis of thirteen podiatrist with and without endorsement, identified competence and autonomy (i.e. need/desire to broaden current scope of practice); social and workplace influences (i.e. access to mentors, training opportunities), and extrinsic motivators (i.e. time and cost of becoming in endorsed) are key barriers and facilitators for podiatrists gaining endorsement. These factors are yet to be explored within the broader podiatry population.

The aim of this research was therefore to investigate the prescribing practices among Australian podiatrists and, to explore barriers and facilitators that influence the uptake and completion of endorsement.

\section{Methods}

\section{Research design}

This research was a quantitative, cross-sectional survey design, conducted between July 2020 and December 2020. The online survey was created and delivered via SurveyMonkey®. Potential participants were provided with written information on the study aims and directives, giving online informed consent prior to commencing the survey. Respondents were advised that

they could withdraw from the survey at any time by closing the browser, with data collected to that point included in the results. Those completing the survey were offered the option to provide an email address if they would like a summary of results supplied, otherwise all survey respondents remained anonymous. Ethical approval was gained from the University of South Australia Human Research Ethics Committee (Approval number 202938). 


\section{AUSTRALIAN PODIATRISTS PRESCRIBING}

\section{Participants and settings}

All registered and practicing Australian podiatrists and podiatric surgeons were eligible to participate $(\mathrm{n}=5759)(12)$. Participants were alerted to, and invited to participate in, the research via the Australian Podiatry Association, Facebook ${ }^{\mathrm{TM}}$, Twitter ${ }^{\mathrm{TM}}$, special interest groups, and through the authors' networks. This approach was particularly chosen to ensure maximum coverage of podiatrists, promote participation and achieve adequate response rate.

\section{Survey design}

Data were collected during a single round, purpose built, self-reported survey. The survey was developed collaboratively by the author group and pilot tested by three podiatrists, who were then excluded from the results, to ensure clarity and appropriateness of question structure, as well as face validity. The survey contained three sections: demographic data including clinical experience, questions pertaining to prescribing practices, and perceptions of the endorsement pathway.

Demographic data included profession (podiatrist or podiatric surgeon), gender, age, state, or territory of most frequent practice, primary role (clinician, administrator, teacher, or educator, researcher), primary work sector (private, public, or both private and public), employment status (self-employed, employed etc.,), and location. Participants then identified as non-endorsed, endorsed, or in-training to be endorsed for prescribing scheduled medicines (in-training), the location of practice where they were most likely to prescribe medications, and length of time since endorsement where relevant.

Questions pertaining to prescribing practices asked participants to identify how often (weekly, monthly, quarterly, annually, never) they prescribed from the medications listed on the Podiatry Board of Australia: Guidelines for endorsement for scheduled medicines (10). The medicines were grouped into: antimycotics, antibacterial, actinic keratosis, drugs for gout, corticosteroid, non-steroidal anti-inflammatories, analgesics, antihistamines, antidotes and antivenoms, local anaesthetics, emergency (anaphylactic reactions), and benzodiazepines. If participants had prescribed from a medication group, a drop-down list asked the specific medicaments prescribed from those approved for use by Australian podiatrists (10). For a full list of responder choices, please see Supplementary Material Table 1. 


\section{AUSTRALIAN PODIATRISTS PRESCRIBING}

Questions concerning barriers and facilitators to endorsement were developed based on the previous qualitative study conducted by Graham and colleagues (15). Specifically, endorsed and in-training participants were asked to identify which facilitators, from a given list, most contributed to their decision to undertake endorsement. Example facilitators were 'It would enable me to offer complete patient care', 'I believe it is an essential skill for effective podiatry practice'. This same group then identified items that made it difficult to complete the requirements for endorsement. Examples include 'The time commitment involved impacted my private life' and 'Limited access to supervisors/mentors'.

\section{Procedure}

Participants were asked to indicate their endorsed status (non-endorsed, in-training, and endorsed), and the survey tool used skip-logic to skip to relevant questions. All responders were asked the same questions regarding demographics, prescription practices and facilitators for endorsement, however, endorsed or in-training podiatrists were asked some additional questions specific to barriers surrounding the endorsement procedure.

\section{Data management}

Participants were categorised by endorsement status for descriptive purposes (e.g., Nonendorsed, Endorsed, and In-training). For questions relating to barriers and facilitators to training (i.e., survey section three), In-training and Endorsed outcomes are pooled as both groups have insight into the training process.

\section{Data analysis}

Data collected were de-identified and exported to Microsoft Excel (Microsoft Corporation (2018)) for descriptive analysis. All responses were presented as reported, except for the length of time respondents have held endorsements. For this question, responses were analysed as five categories of duration $(<1,1-4,5-9,10-15$ years) to align with durations reported by Australian Health Practitioner Regulation Agency (AHPRA) registrant summary report. Results are presented as frequencies.

\section{Results}




\section{AUSTRALIAN PODIATRISTS PRESCRIBING}

Of the 229 participants who agreed to take part in the survey, four failed to report their profession and were excluded from all further analyses. A total of 225 registered Australian podiatrists were included in the results for this survey, four of whom were podiatric surgeons.

\section{Demographic information \& clinical experience of respondents}

Descriptive data of registered podiatrists who took part in the survey are presented in Table 1. Respondents were predominantly female, aged 25-45, working in the private sector. Most endorsed prescribers practiced in Queensland (33\%) or Victoria (36\%), worked within the metropolitan regions of Australia (86\%) in private practice (73\%), with over 10 years of clinical experience (79\%). Most endorsed prescribers had less than ten years of endorsement (86\%) and none of the participants who reported that they were endorsed prescribers or in training worked in remote or very remote parts of Australia. As presented in Table 1, the survey participants reflect the AHPRA registrant data published in March 2021 (12).

Of the 225 participants who held general registration, approximately one quarter $(25.3 \%)$ were endorsed $(n=33,14.7 \%)$ or in training $(n=24,10.7 \%)$ (this included those completed and awaiting board approval). All podiatric surgeons $(n=4)$ were endorsed as per requirements for surgeon registration. Of the 168 non-endorsed respondents, $66.0 \%$ reported that they would like to undertake training to become an endorsed prescriber. 


\section{AUSTRALIAN PODIATRISTS PRESCRIBING}

Table 1: Demographic details of participants and comparisons with all registered Australian podiatrists

\begin{tabular}{|c|c|c|c|c|}
\hline \multirow[t]{2}{*}{ Demographics } & \multirow{2}{*}{$\begin{array}{l}\text { AHPRA } \\
\text { registrant data }\end{array}$} & \multicolumn{3}{|c|}{ Participants Endorsement status, $n=225$} \\
\hline & & Non-endorsed & Endorsed & In-training \\
\hline Total registered, $\mathrm{n}$ (endorsed) & $5783(162)$ & 168 & 33 & 24 \\
\hline General registration & 5604 & 168 & 29 & 24 \\
\hline Podiatric surgeon & 36 & & 4 & \\
\hline \multicolumn{5}{|l|}{ Sex } \\
\hline Male & 2370 & 52 & 15 & 8 \\
\hline Female & 3413 & 116 & 18 & 15 \\
\hline \multicolumn{5}{|l|}{ Age } \\
\hline$<25$ & 344 & 14 & 0 & 4 \\
\hline $25-29$ & 1204 & 31 & 2 & 5 \\
\hline $30-34$ & 1104 & 29 & 8 & 6 \\
\hline $35-39$ & 793 & 29 & 7 & 2 \\
\hline $40-44$ & 613 & 21 & 1 & 1 \\
\hline $45-49$ & 587 & 15 & 1 & 4 \\
\hline $50-54$ & 459 & 13 & 5 & 2 \\
\hline $55-59$ & 347 & 11 & 6 & 0 \\
\hline$>60$ & 223 & 5 & 3 & 0 \\
\hline \multicolumn{5}{|l|}{ State, $n$ (endorsed) } \\
\hline \begin{tabular}{l|l} 
& ACT \\
\end{tabular} & $76(2)$ & 1 & 0 & 0 \\
\hline NSW & $1631(16)$ & 29 & 2 & 0 \\
\hline NT & $30(1)$ & 1 & 0 & 1 \\
\hline QLD & $999(41)$ & 18 & 11 & 0 \\
\hline $\mathrm{SA}$ & $534(18)$ & 60 & 7 & 5 \\
\hline TAS & $119(4)$ & 1 & 0 & 2 \\
\hline VIC & $1818(49)$ & 55 & 12 & 8 \\
\hline WA & $512(31)$ & 3 & 1 & 8 \\
\hline \multicolumn{5}{|l|}{ Work sector } \\
\hline Public and Private & & 12 & 4 & 1 \\
\hline Private sector-employee & & 44 & 4 & 7 \\
\hline Private-other & & 5 & 1 & 0 \\
\hline Private-self-employed & & 67 & 15 & 8 \\
\hline Public sector & & 40 & 9 & 10 \\
\hline \multicolumn{5}{|l|}{ Location* } \\
\hline Major Cities of Australia & & 108 & 25 & 15 \\
\hline Inner regional Centre & & 25 & 4 & 6 \\
\hline Outer regional Centre & & 24 & 4 & 3 \\
\hline Remote & & 10 & 0 & 0 \\
\hline Very remote community & & 1 & 0 & 0 \\
\hline \multicolumn{5}{|l|}{ Years of practice } \\
\hline $0-4$ & & 42 & 1 & 13 \\
\hline $5-9$ & & 27 & 6 & 2 \\
\hline
\end{tabular}


AUSTRALIAN PODIATRISTS PRESCRIBING

\begin{tabular}{|c|c|c|c|}
\hline $10-14$ & 32 & 10 & 3 \\
\hline $15-19$ & 24 & 2 & \\
\hline$>20$ & 43 & 14 & 21 \\
\hline \multicolumn{4}{|l|}{ Years of endorsement } \\
\hline$<1$ year & $\mathrm{n} / \mathrm{a}$ & 4 & $\mathrm{n} / \mathrm{a}$ \\
\hline $1-4$ years & $\mathrm{n} / \mathrm{a}$ & 10 & $\mathrm{n} / \mathrm{a}$ \\
\hline $5-9$ years & $\mathrm{n} / \mathrm{a}$ & 10 & $\mathrm{n} / \mathrm{a}$ \\
\hline 10-15 years & $\mathrm{n} / \mathrm{a}$ & 4 & $\mathrm{n} / \mathrm{a}$ \\
\hline \multicolumn{4}{|l|}{ Setting most often prescribe } \\
\hline Private practice & $\mathrm{n} / \mathrm{a}$ & 15 & $\mathrm{n} / \mathrm{a}$ \\
\hline $\begin{array}{l}\text { Community health care } \\
\text { service }\end{array}$ & $\mathrm{n} / \mathrm{a}$ & 1 & $\mathrm{n} / \mathrm{a}$ \\
\hline Outpatient service & $\mathrm{n} / \mathrm{a}$ & 6 & $\mathrm{n} / \mathrm{a}$ \\
\hline Aged care & $\mathrm{n} / \mathrm{a}$ & 0 & $\mathrm{n} / \mathrm{a}$ \\
\hline Hospital & $\mathrm{n} / \mathrm{a}$ & 4 & $\mathrm{n} / \mathrm{a}$ \\
\hline Education facility & $\mathrm{n} / \mathrm{a}$ & 1 & $\mathrm{n} / \mathrm{a}$ \\
\hline Sports center & $\mathrm{n} / \mathrm{a}$ & 0 & $\mathrm{n} / \mathrm{a}$ \\
\hline Locum private practice & $\mathrm{n} / \mathrm{a}$ & 0 & $\mathrm{n} / \mathrm{a}$ \\
\hline Aboriginal health service & $\mathrm{n} / \mathrm{a}$ & 0 & $\mathrm{n} / \mathrm{a}$ \\
\hline
\end{tabular}

*Location was defined using the Australian Statistical Geography Standard (ASGS), which defines relative remoteness, using the Accessibility and Remoteness Index of Australia (ARIA+). Further detail has been reported elsewhere. (16)

Note: In-training = In training for endorsement 


\section{AUSTRALIAN PODIATRISTS PRESCRIBING}

\section{Prescribing practices}

The frequency of medications prescribed over the last twelve-month period (weekly, monthly, quarterly, yearly, never) according to endorsement status are presented in Figure 1. The groups of medications most frequently prescribed (on a weekly or monthly basis) by all respondents include local anaesthetics, antibacterial agents, analgesia, antimycotics, and non-steroidal antiinflammatory drugs. The most common indications reported for prescribing these medications

include nail surgery (71\%), foot infections and ulcerations (88\%), post-operative pain (67\%), and mycosis $(95 \%)$ respectively.

The antidotes and antivenom class were not prescribed by any responders, and emergency (anaphylactic reactions) medications were only occasionally prescribed by Endorsed participants. As expected, there are some medications not prescribed by Non-endorsed and In-training participants due to requiring endorsement to do so, for example, drugs for gout. 
Figure 1: Frequency of medication class prescribed over the last twelve months according to endorsement status

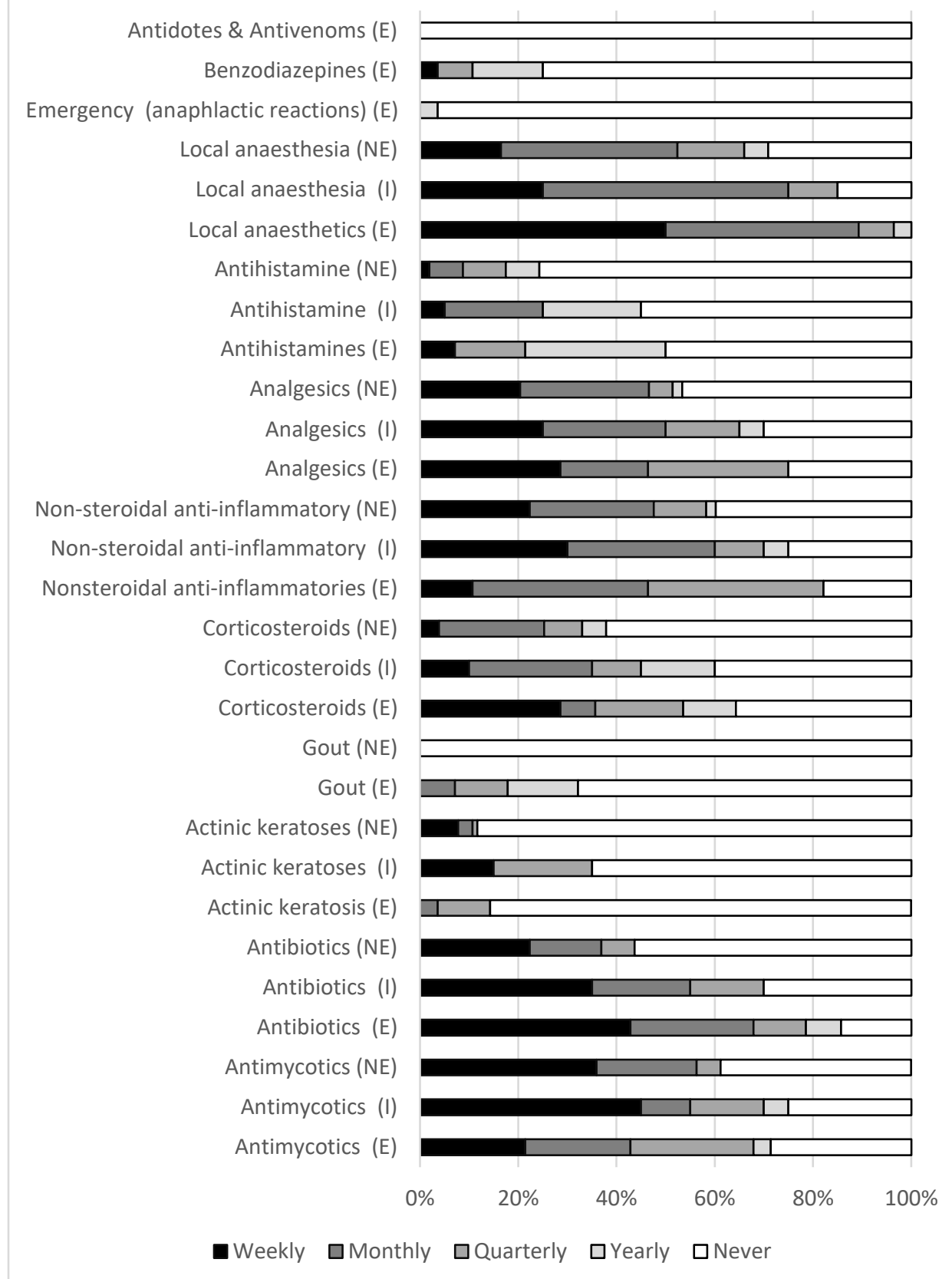

Note: (E) Endorsed (NE) Non-endorsed (I) In-training 


\section{AUSTRALIAN PODIATRISTS PRESCRIBING}

The prescribing practices of Schedule 2 and 3 medicines by participants over the last 12 months, are presented in Figure 2 according to endorsement status. A larger proportion of Endorsed participants, or those In-training, reported prescribing Schedule 2 or 3 medication over the last 12 months compared to Non-endorsed participants. The most prescribed Schedule 2 medications were ibuprofen, paracetamol, and topical terbinafine, irrespective of endorsement status. The most prescribed Schedule 4 medicines among Endorsed participants included lignocaine (84\%), Cephalexin (68\%), Flucloxacillin (68\%), and Amoxicillin with Clavulanic acid (61\%).

Lignocaine, a Schedule 4 medicine (local anaesthetic) that podiatrists have long been able to prescribe and administer without further endorsement, was the most prescribed medication by all participants ( $84 \%$ of Endorsed podiatrists, $75 \%$ of podiatrists In-training, $55 \%$ of Non-endorsed participants). Except for lignocaine, approximately 1 in 5 Endorsed participants reported not prescribing medications over the last twelve months. The frequency of prescribing specific medications (including Schedule 4 medicines) is provided in Supplement Material Table 1. 


\section{AUSTRALIAN PODIATRISTS PRESCRIBING}

Figure 2. Prescribing patterns of Schedule 2 and 3 medicines, and local anaesthetic by podiatrists over the last 12 months, by endorsement status

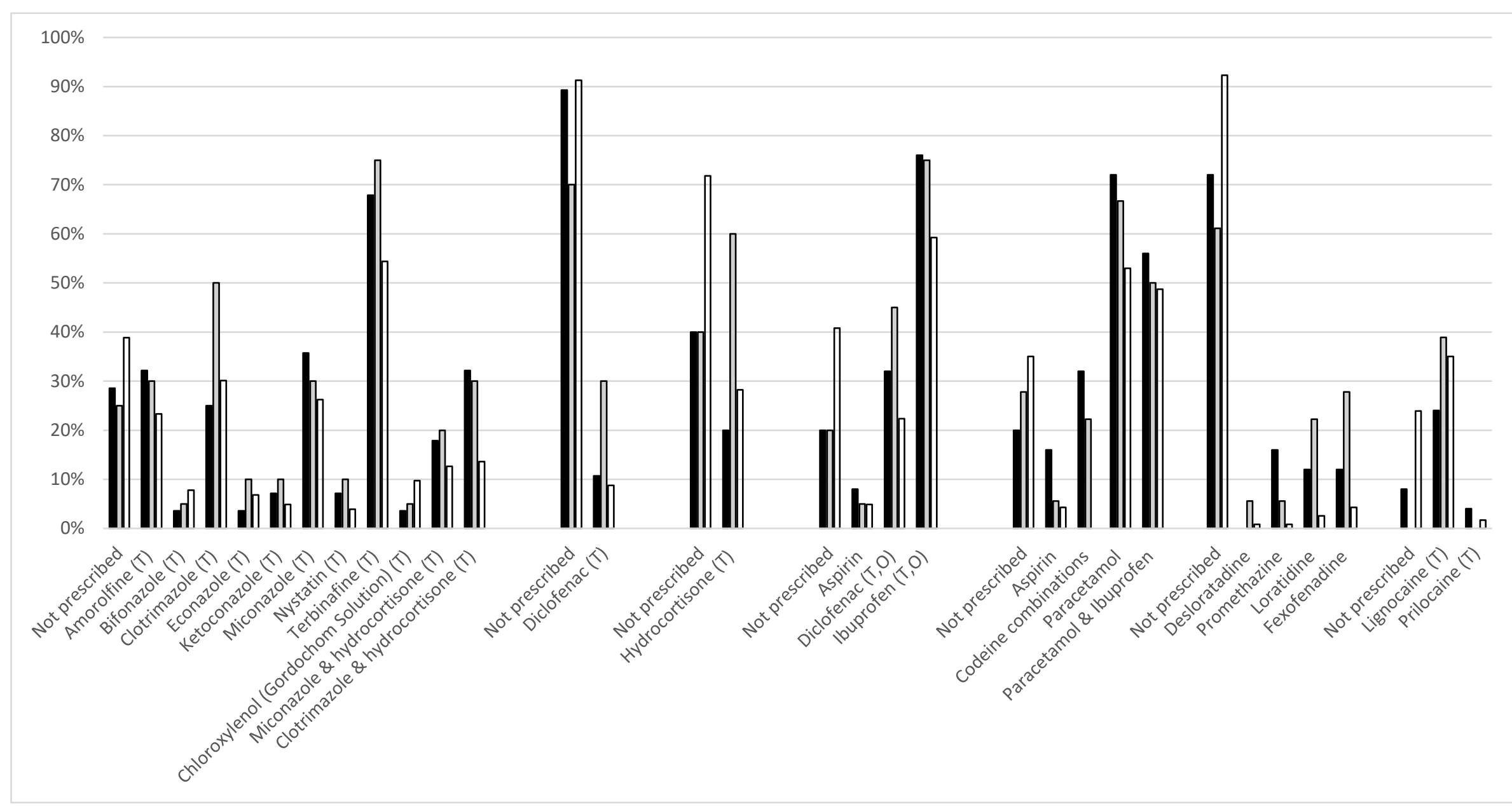

Endorsed $\square$ In-training $\square$ Not Endorsed

Note: topical preparations are denoted by $(T)$ and oral preparations are denoted by $(O)$ 
AUSTRALIAN PODIATRISTS PRESCRIBING

\section{Perceptions of the endorsement pathway}

\section{Facilitators of endorsement}

The frequency of facilitators for endorsement is provided in Figure 3. All of the Endorsed participants reported 'It would enable me to provide complete patient care', compared with $87.5 \%$ of In-training and $64.5 \%$ of Non-endorsed participants. Irrespective of endorsement status the items 'Broadening my scope of practice to offer a higher level of patient care' was a highly reported facilitator along with 'To offer streamlined processes of patient care' and 'I like to extend my knowledge'.

Compared to Endorsed participants (0.1\%), Non-endorsed participants (30.8\%) identified 'If endorsed podiatrists got a higher Medicare rebate' as an important factor in deciding to undertake training. In-training (44.4\%) and Non-endorsed (33.6\%) participants had similar response rates to 'Access to prescriptions from alternate sources', while this item had low response rates from Endorsed participants (8.3\%). Compared to Endorsed (66.7\%) and InTraining participants $(61.1 \%)$, fewer Non-endorsed participants $(27.1 \%)$ reported ' $\mathrm{I}$ believe it is an essential skill for effective podiatry practice'. 


\section{AUSTRALIAN PODIATRISTS PRESCRIBING}

Figure 3. Factors perceived to be important when deciding to undertake endorsement, by endorsement status

Working in an environment with other endorsed prescribers

Support from other health professionals

If endorsed prescribers got a higher Medicare rebate

Support / encouragement from leadership / employer

Time and allocated education within public sector

I would like to take advantage of having just completed my university study and utilise that knowledge before I lose it

I like to extend my knowledge

I believe it is an essential skill for effective podiatry practice

If it was an essential requirement of my position

To become a valued team member

It would provide future career opportunities and job security

Access to prescriptions from alternative sources

Broadening my scope of practice to offer a higher level of patient care

The client profile I see could benefit from my being able to prescribe

To offer streamlined process of patient care

It would enable me to offer complete patient care
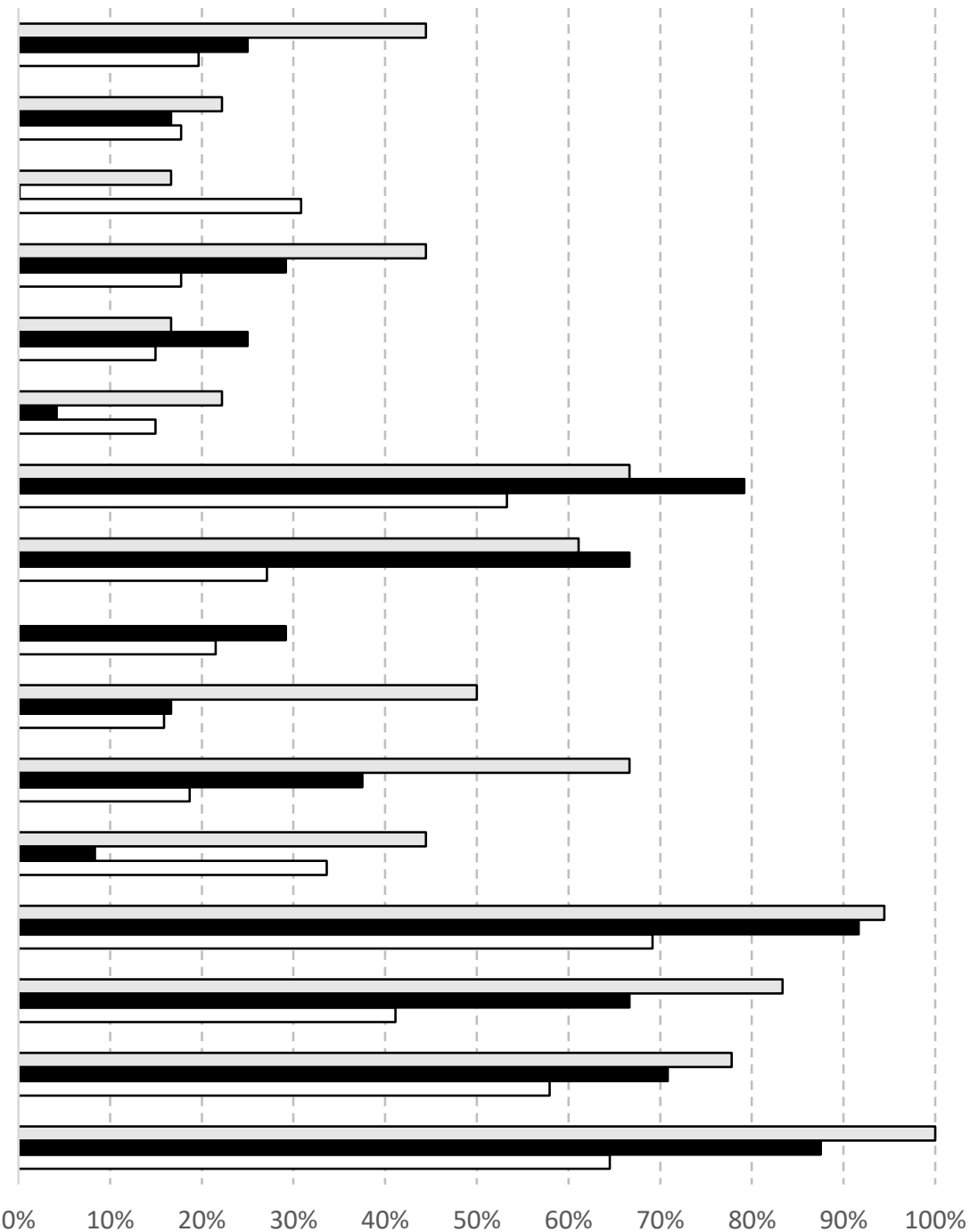

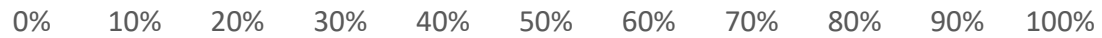

\section{Endorsed $\square$ In-training $\square$ Non-endorsed}




\section{AUSTRALIAN PODIATRISTS PRESCRIBING}

\section{Barriers of endorsement}

The results for barriers to endorsement are listed in Table 2. For those that were Endorsed or In-training the most highly reported barriers were 'Prolonged approval / review process from the Board' (75.0\%), 'The time commitment involved impacted my private life' $(62.5 \%)$, and 'Time away from work' (45.8\%). Of note, very few (12.5\%) Endorsed participants identified that they had 'No difficulties' associated with completing the requirements for endorsement.

More than half of Non-endorsed participants reported barriers associated with the training process and time requirements. Some of the most highly reported responses were 'Limited access to supervisors/ mentors' $(60.8 \%)$, and 'The cost of training is prohibitive - University or time away from work' (42.8\%), and 'Lack of structured clinical training' (45.8\%), and 'I do not have the time needed to undertake training' (40.2\%). Many Non-endorsed participants reported 'It is harder in private practice/non-hospital-based positions than within the public hospital sector' (33.6\%). This perception may be because podiatrists in large hospitals have access to a broad range of supervised practice opportunities. 'Lack of PBS funding for podiatry-prescribed scripts' (42\%), 'You can be a successful podiatrist without having endorsement' (32.7\%), 'The easy availability of scripts from alternate sources' (29.0\%), and 'Lack of professional role identity - Our patients are not aware we can prescribe' (20.6\%) were also identified. 


\section{AUSTRALIAN PODIATRISTS PRESCRIBING}

Table 2: Items that respondents thought made endorsement difficult to complete (Endorsed and In-training participants) or acted as barriers to undertaking endorsement (Non-endorsed participants) in rank order.

\begin{tabular}{|c|c|}
\hline $\begin{array}{l}\text { Factors that made it difficult to complete the requirements for endorsement, as reported by endorsed } \\
\text { respondents and podiatrists in training }\end{array}$ & $\begin{array}{l}\text { Endorsed/in } \\
\text { training }\end{array}$ \\
\hline Prolonged approval / review process from the Board & $75.0 \%$ \\
\hline The time commitment involved impacted my private life & $62.5 \%$ \\
\hline Time away from work & $45.8 \%$ \\
\hline Rural or remote location offers logistical barriers to access training & $20.8 \%$ \\
\hline No tangible incentives to undertake training & $20.8 \%$ \\
\hline Limited access to supervisors / mentors & $20.8 \%$ \\
\hline Other (please specify) & $16.7 \%$ \\
\hline Limited support from supervisors / mentors & $12.5 \%$ \\
\hline Not applicable - no difficulties & $12.5 \%$ \\
\hline Multiple mentees shadowing one mentor & $4.2 \%$ \\
\hline Barriers to undertaking endorsement, as reported by non-endorsed respondents & Non-endorsed \\
\hline Limited access to supervisors/mentors & $60.8 \%$ \\
\hline The cost of training is prohibitive - uni or time away from work & $53.3 \%$ \\
\hline Lack of structured clinical training & $45.8 \%$ \\
\hline Lack of PBS funding & $42.1 \%$ \\
\hline I do not have the time needed to undertake training & $40.2 \%$ \\
\hline It is harder in private practice/non-hospital-based positions than within the public hospital sector & $33.6 \%$ \\
\hline You can be a successful podiatrist without having endorsement & $32.7 \%$ \\
\hline No tangible incentives to undertake training & $31.8 \%$ \\
\hline Easy and convenient access to prescriptions from alternative sources & $29.0 \%$ \\
\hline Lack of understanding of the endorsement training process & $21.5 \%$ \\
\hline Lack of professional role identity - Our patients are not aware we can prescribe & $20.6 \%$ \\
\hline The profile of patients I treat do not require this service & $18.7 \%$ \\
\hline Rural or remote location offers logistical barriers to access training & $17.8 \%$ \\
\hline Other (please specify) & $16.8 \%$ \\
\hline I am concerned the other health professionals I work with would not approve & $10.3 \%$ \\
\hline
\end{tabular}




\section{AUSTRALIAN PODIATRISTS PRESCRIBING}

Staff shortages in rural or remote areas

I'm towards the end of my professional career

I prefer to use more natural interventions rather than prescription medicines

I have just started practicing and would like to get some experience before I undertake endorsement

It is harder within the public hospital sector than in private practice/non-hospital-based positions

Note: participants could select multiple responses, i.e. all responses that apply. 


\section{AUSTRALIAN PODIATRISTS PRESCRIBING}

\section{Discussion}

This is the first known survey of Australian podiatrists' prescribing practices and barriers and facilitators to endorsement for scheduled medicines. Findings from 225 registered podiatrists indicate that approximately one third of survey participants were endorsed podiatrists, well above the percent of endorsed podiatrists (less than 3\%) in the Australian podiatry population, which may reflect a greater interest in the survey topic among this group. The most common medications prescribed by all podiatrists were local anaesthetics, antimycotics, antibiotics, and analgesics. These findings are consistent with other studies that examine prescribing practices among non-medical prescribers $(17,18)$. Taken together these findings suggest the management of pain and infection are areas of prescribing where patients' patterns of receiving their medications is undergoing change.

Podiatry, with its known association with chronic disease is well placed in the primary health care setting to reduce burden on General Practitioners and the public health care system $(4,9)$. This could be achieved through promoting podiatry endorsement as a majority of Non-endorsed participants reported they would like to become an endorsed prescriber. However, this intention is not converted into behaviour as the uptake of endorsement for scheduled medicines within the profession remains low. This intention-behaviour gap could be partly explained as Endorsed participants reported numerous barriers within the training process, with only $12.5 \%$ of Endorsed participants reporting no difficulties. Further, $75 \%$ indicated that the wait to receive the award after completing training was prolonged. Steps taken by the Podiatry Board of Australia to reduce the wait time to obtain endorsement may address this concern in the future.

Current endorsement pathways require a high level of motivation. Individuals are tasked with costly enrolment into post-graduate courses (with associated non-Commonwealth supported fees), the commitment to undertake self-directed online case studies, identify and approach a mentor, identify and organise supervised practice opportunities over a broad range of areas, and complete a portfolio of evidence. Hence, it is not unexpected that barriers related to endorsement were amongst the most highly reported barriers by Non-endorsed participants. In addition, Nonendorsed participants frequently identified a 'Lack of understanding of the endorsement training process'. While this could reflect a lack of intent or motivation to engage with endorsement training, it may also reflect the onerous training process. 


\section{AUSTRALIAN PODIATRISTS PRESCRIBING}

The 'Lack of PBS funding' was reported as a considerable barrier for Non-endorsed participants to undertake endorsement training. Eligibility to prescribe medications under the PBS has been viewed as an important factor in providing full episodes of patient care elsewhere $(19,20)$. Without PBS subsidies, podiatry patients may incur greater out-of-pocket expenses or choose to return to their General Practitioner for prescriptions, increasing public and healthcare costs. In addition, podiatrists do not have access to government subsidy for pathology testing and cannot request haematology-based laboratory testing, yet these are often required to provide full episodes of patient care and ensure patient safety. These findings may, in-part, explain the relatively high proportion of Endorsed participants not prescribing any medications and the prescribing patterns for antifungal medications observed. Topical antifungal therapies (which are known to have limited efficacy for the treatment of onychomycosis (21)), do not require pathology testing to prescribe and manage and were recommended by up to $67 \%$ of Endorsed participants over the last twelve months. While oral terbinafine, which has high quality evidence for efficacy in the treatment of onychomycosis but requires both pathology testing and liver function monitoring (22), was only prescribed by $25 \%$ of Endorsed participants over the last twelve months.

Identifying factors that motivate podiatrists to become endorsed is an important step in developing strategies to increase engagement and participation. The findings of this survey build on the qualitative interviews by Graham et al (15) confirming that the self-determination theory (SDT) $(23,24)$ can provide insights into the drives of motivation. This universal motivational and personality framework is commonly applied in education and health settings and is based on the concept that people naturally develop through acquiring knowledge, skill, and habits they observe that support their basic psychological needs of autonomy, competence, and relatedness (25).

Self-determination theory posits that motivation to undertake learning can be represented on a continuum from extrinsic motivation (e.g. financial rewards) through to intrinsic motivation (e.g. curiosity or finding the content appealing and interesting) (25). In SDT, internalisation occurs when a behaviour becomes a personally endorsed value such that the behaviour is in harmony with the broader values, commitments, and interests of the person $(26,27)$. In-training participants had the highest reporting of 'I believe it is an essential skill for effective podiatry 


\section{AUSTRALIAN PODIATRISTS PRESCRIBING}

practice', followed by endorsed participants, suggesting for them prescribing may have become an internalised behaviour that motivated these participants to overcome the onerous training process.

Several studies have supported aspects of SDT on an organizational level (28). The history of local anaesthetic (LA) use in podiatry could be one example of internalising prescribing as a behaviour on a profession wide level. Local anaesthetic was introduced as part of undergraduate podiatry training in Australia in 1978 (29) and has seen a wide uptake such that it is now seen by the profession as an essential skill. Findings from this survey also indicate that LA were medications non-endorsed participants frequently prescribed.

Self-determination theory hypothesises that the need to be connected to others and to be an effective member of the social environment supports the tendency to internalise the values and regulatory processes of their surroundings (28). In-training participants had the highest reporting of the social and workplace influences of 'Becoming a valued member of a team' and 'Support from employers'. Similarly, In-training participants reported higher levels than Non-endorsed participants of 'Working in an environment with other endorsed prescribers', suggesting observing prescribing in the workplace can motivate an individual to master that skill to integrate into the larger social structure of the workplace (25). The lack of internalization by Nonendorsed participants is further supported by reporting 'You can be a successful podiatrist without having endorsement'. Endorsed participants indicated the intrinsic motivator such as 'I like to extend my knowledge' for participating in endorsement training. This may suggest that such intrinsic motivation is more more likely to motivate podiatrists to action than the extrinsic factors such 'Lack of PBS funding' and 'No tangible incentives to undertake training'. Interestingly, these were reported as barriers by Non-endorsed participants (25).

\section{Future directions}

The second most frequently reported barrier by Endorsed participants was 'The time commitment involved impacted my private life'. Training systems that provide flexible learning environments to assist with balancing work and other commitments may overcome this barrier. Plans to incorporate endorsement training into the undergraduate accredited programs in Australia are one such strategy to assist in increasing endorsement rates in the future podiatry workforce. However, this poses new challenges such as curriculum creep, staffing and 


\section{AUSTRALIAN PODIATRISTS PRESCRIBING}

resourcing requirements. Forward planning to meet the required mentors for prescription practices in the new undergraduate pathways will maximise rates of participation in endorsement. Supporting podiatrists working in the academic environment to become endorsed could be considered a priority.

This research supports the premise of SDT theory that social context can motivate behaviour change. Combined with the finding that supervisor and mentor access are a major barrier suggests that supporting podiatrists in leadership roles in clinical settings may be a strategy that could have considerable short-term impact by improving access to mentors as well as increase opportunities to internalise prescribing behaviour in the podiatry profession. One strategy could be to establish a formalised leadership and mentoring framework, as well as communities of practice where podiatrists support each other and increase capacity.

Podiatry could explore strategies used by other allied health groups included in the legislative changes for non-medical prescribing. For example, in the Australian optometry profession which is comparable in size to podiatry $(\mathrm{N}=6207), 68 \%$ of optometrists hold an endorsement for scheduled medicines qualification (30). In addition to incorporating therapeutic training into undergraduate degrees since 2002 (31), in optometry there is a streamlined, post graduate academic pathway. A one-year postgraduate certificate in Ocular Therapeutics is offered by two accredited independent optometry education institutions. The cost to students is approximately $\$ 10,000$ and includes support to meet required clinical hours, such that students graduate with a formalised qualification recognised by their registration body. To the authors knowledge, there are currently 2 universities offering the postgraduate podiatric therapeutic component of the pathway. However, there are currently no Australian providers that offer courses that incorporate all components of the pathway.

\section{Strengths and limitations}

While this survey examines a sample of Australian podiatrists that share demographic characteristics consistent with the Podiatry Board of Australia registrant data, there are limitations that must be addressed. Firstly, the final sample was relatively small, reflecting approximately $4 \%$ of the total Australian podiatry population. Caution is therefore needed when generalising study findings to the entire podiatry population. Secondly data collected are selfreported and may be prone to reporting bias such as recall bias and social desirability bias (32). 


\section{AUSTRALIAN PODIATRISTS PRESCRIBING}

Lastly, we did not differentiate the separate pathways available to become an endorsed prescriber. Since several endorsement pathways exist, it is possible that perceptions relating to factors that made endorsement training difficult to complete, may vary according to pathway.

\section{Conclusion}

This is the first known research to examine the prescribing practices of podiatrists within Australia, with a key outcome being that podiatrists predominantly prescribe to assist pain, inflammatory, or infectious conditions. However, lack of PBS funding and pathology testing access limit podiatrists' ability to provide full episodes of patient care. Therefore, the valuable benefits of streamlined care, improved patient access, and improved efficiencies in the health system may not be fully realised.

Approaches that improve access to mentors and a broad range of supervised practice, such as a increased numbers of endorsed podiatrists or a formalised leadership and mentoring framework are likely strategies that that could improve access to training opportunities. It was also suggested that some barriers to endorsement could be addressed by internalising prescribing as a behaviour in the podiatry profession through supporting staff within leadership roles and teaching institutions to engage with and model the endorsement process. The plan to incorporate training into undergraduate education has been demonstrated in the past to be effective when used with the prescription of LA. While this may be a long-term strategy, in the short term, improving access to mentors and incentives for the current workforce to undertake endorsement training should be actively considered. 


\section{Abbreviations}

LA local anaesthetic

SDT self-determination theory

\section{Availability of data and materials}

The datasets used and/or analysed during the current study are available from the corresponding author on reasonable request.

\section{Acknowledgments}

The authors wish to thank all participants who volunteered to take part in this survey.

\section{Funding}

This work is supported by an Australian Podiatry and Education Research Foundation research grant.

\section{Author information - Affiliations}

Allied Health \& Human Performance, The University of South Australia, North Terrace, Adelaide, SA, 5000, Australia

Kristin Graham, Helen A. Banwell, Ryan S. Causby, Saravana Kumar, \& Lisa Matricciani Faculty of Health, School, Clinical Sciences, Queensland University of Technology, Brisbane, Australia

Lisa Nissen

\section{Contributions}

KG conceived of the study, HB, RC, LN, and SK developed the survey, LM and KG drafted the manuscript. LM conducted data analysis. $\mathrm{HB}, \mathrm{RC}, \mathrm{KG}, \mathrm{LN}$, and SK assisted with drafting the manuscript and data analysis. KG, HB, RC, SK, and LN made contributions to the study conception and design. All authors read, commented on, and approved the final manuscript.

\section{Corresponding author}

Correspondence to Kristin Graham 
AUSTRALIAN PODIATRISTS PRESCRIBING

\section{Ethics approval and consent to participate}

Ethical approval was obtained from the Human Research Ethics Committee from the University of South Australia [Protocol number 202938]. All participants provided written informed consent.

\section{Consent for publication}

Not applicable. The consent forms signed by all participant included information that the findings would be used in a publication.

\section{Competing interests}

The authors declare they have no competing interests. 
References

1. Duckett S, Breadon PJGIR, September. Access all areas: new solutions for GP shortages in rural Australia. 2013.

2. McLachlan AJ, Aslani PJAp. National Medicines Policy 2.0: a vision for the future. 2020;43(1):24.

3. Nissen L, Kyle G, Stowasser D, Lum E, Jones A, McLean C, et al. Non-medical prescribing: An exploration of likely nature of, and contingencies for, developing a nationally consistent approach to prescribing by non-medical health professionals-Final Report 1 June 2010. 2010.

4. Page AT, Cross AJ, Elliott RA, Pond D, Dooley M, Beanland C, et al. Integrate healthcare to provide multidisciplinary consumer-centred medication management: report from a working group formed from the National Stakeholders' Meeting for the Quality Use of Medicines to Optimise Ageing in Older Australians. 2018;48(5):459-66.

5. Bennett CJFRotNH, Hospitals Reform Commission C. National Health and Hospitals Reform Commission: A Healthier Future for All Australians. 2009.

6. Shaw B, Chisholm OJMJoA. Australia's National Medicines Policy is outdated and in need of review. 2019;211(6):252-4. e1.

7. Weeks G, George J, Maclure K, Stewart DJCDoSR. Non-medical prescribing versus medical prescribing for acute and chronic disease management in primary and secondary care. 2016(11).

8. Couch AG, Foo J, James AM, Maloney S, Williams CMJJof, research a. Implementing a podiatry prescribing mentoring program in a public health service: a cost-description study. 2018;11(1):1-8.

9. Bennett $\mathrm{C}$, . National Health and Hospitals Reform Commission: A Healthier Future for All Australians. Canberra; 2009.

10. AHPRA. Podiatry Board of Australia: Guidelines for endorsement for scheduled medicines. . 2018.

11. Hope DL, King MAJJol, medicine. Asynchronous medicines legislation for non-medical prescribing. 2017;24:656-61.

12. AHPRA. Podiatry Board of Australia Registrant data. In: Board P, editor. 2021.

13. Borthwick AM, Short AJ, Nancarrow SA, Boyce R. Non-medical prescribing in Australasia and the UK: the case of podiatry. Journal of foot and ankle research. 2010;3(1):1-10.

14. Liamputtong P. Qualitative data analysis: conceptual and practical considerations. Health promotion journal of Australia. 2009;20(2):133-9.

15. Graham K, Banwell HA, Causby RS, Kumar S, Tian EJ, Nissen L. Barriers to and facilitators of endorsement for scheduled medicines in podiatry: a qualitative descriptive study. Journal of Foot and Ankle Research. 2021;14(1):1-11.

16. statistics ABo. 1270.0.55.005 - Australian Statistical Geography Standard (ASGS): Volume 5 Remoteness Structure, July 20162018 [Available from: https://www.abs.gov.au/ausstats/abs@.nsf/Latestproducts/1270.0.55.005Main\%20Features1 5July\%202016?opendocument\&tabname=Summary\&prodno $=1270.0 .55 .005 \&$ issue $=J u l y \% 2020$ 16\&num $=\&$ view $=$.

17. Fong J, Cashin A, Buckley T. Models of prescribing, scope of practice, and medicines prescribed, a survey of nurse practitioners. Journal of Advanced Nursing. 2020;76(9):2311-22.

18. Currie J, Chiarella M, Buckley T. Privately practicing nurse practitioner services in Australia and patient access to care: results from realist interviews. Journal of the American Association of Nurse Practitioners. 2018;30(6):344-53. 


\section{AUSTRALIAN PODIATRISTS PRESCRIBING}

19. Donovan J, Tsuyuki RT, Al Hamarneh YN, Bajorek B. Barriers to a full scope of pharmacy practice in primary care: A systematic review of pharmacists' access to laboratory testing. Canadian Pharmacists Journal/Revue des Pharmaciens du Canada. 2019;152(5):317-33.

20. Fong J, Buckley T, Cashin A. Nurse practitioner prescribing: an international perspective. Nursing: Research and Reviews. 2015;5:99-108.

21. Crawford F, Hollis S. Topical treatments for fungal infections of the skin and nails of the foot. Cochrane Database of Systematic Reviews. 2007(3).

22. Therapeutic Guidelines Limited. eTG complete [digital] Melbourne [Available from: https://www.tg.org.au.

23. Deci EL, Ryan RMJPi. The" what" and" why" of goal pursuits: Human needs and the selfdetermination of behavior. 2000;11(4):227-68.

24. Ryan RM, Deci ELJAp. Self-determination theory and the facilitation of intrinsic motivation, social development, and well-being. 2000;55(1):68.

25. Maurer T, Allen D, Gatch DB, Shankar P, Sturges DJIJoAHS, Practice. Students' academic motivations in allied health classes. 2012;10(1):6.

26. Vansteenkiste M, Aelterman N, De Muynck G-J, Haerens L, Patall E, Reeve JJTJoEE. Fostering personal meaning and self-relevance: A self-determination theory perspective on internalization. 2018;86(1):30-49.

27. Ryan RM. Psychological needs and the facilitation of integrative processes. Journal of personality. 1995;63(3):397-427.

28. Gagné M, Deci EL. Self-determination theory and work motivation. Journal of Organizational behavior. 2005;26(4):331-62.

29. Tollafield D. When did podiatrists first use local anaesthetic? : Consulting Foot Pain; 2021 [Available from: https://consultingfootpain.co.uk/when-did-podiatrists-first-use-localanaesthetic/.

30. Althubaiti A. Information bias in health research: definition, pitfalls, and adjustment methods. Journal of multidisciplinary healthcare. 2016;9:211.

31. Optometry Board of Australia, 2021, Registrant Data - September 2021. Optometry board AHPRA, accessed 9/11/21 https://www.optometryboard.gov.au/about/statistics.aspx

32. Ko \& Huang, 2021, Ocular Therapeutics, Mivision The Opthalmaic Journal, accessed 9/11/21 https://www.mivision.com.au/2010/05/ocular-therapeutics/ 
AUSTRALIAN PODIATRISTS PRESCRIBING 


\section{Supplementary Files}

This is a list of supplementary files associated with this preprint. Click to download.

- GrahamSupplementaryMaterial.docx 